\title{
Studi tentang Pengaruh Pembelajaran Kewirausahaan Terhadap Minat Berwirausaha Siswa di Era Revolusi 4.0
}

\section{Study of the Effect of Entrepreneurship Education on Student Entrepreneurial Intention in the Revolutionary Era 4.0}

\author{
Amelia Mustikawati ${ }^{\text {a, }}{ }^{*}$, Kurjono ${ }^{\text {b, } 2}$ \\ a,b Program Studi Pendidikan Ekonomi, Sekolah Pascasarjana, Universitas Pendidikan Indonesia, Indonesia \\ ${ }^{1}$ ameliamustikawati@upi.edu*; ${ }^{2}$ kurjono@upi.edu \\ *korespondensi penulis
}

\begin{tabular}{ll}
\hline \multicolumn{2}{l}{ Informasi artikel } \\
\hline Sejarah artikel: \\
Diterima & $: 6$ Juli 2020 \\
Revisi & $: 5$ Agustus 2020 \\
Dipublikasikan & $: 14$ Agustus 2020 \\
\hline
\end{tabular}

\section{ABSTRAK}

Penelitian ini bertujuan untuk mengetahui dan menganalis pengaruh pembelajaran kewirausahaan terhadap minat berwirausaha siswa di era revolusi 4.0. Pembelajaran kewirausahaan diukur melalui indikator

Kata kunci:

Pembelajaran Kewirausahaan

Minat Berwirausaha

Era Revolusi 4.0

enterprenurial awareness education, education for start-up, education for enterprenurial dynamic dan contrinuining education for enterpernurship. Minat berwirausaha diukur melalui indikator preference, desire dan plan. Metode penelitian yang digunakan adalah metode survei eksplanatori. Teknik pengumpulan data melalui penyebaran kuesioner yang dibagikan kepada siswa Sekolah Menengah Kejuruan (SMK) Negeri 2 Tasikmalaya. Instrumen penelitian diuji melalui uji validitas dan uji realibitas. Populasi penelitian ini adalah seluruh siswa SMK Negeri 2 Tasikmalaya sebanyak 1.545 siswa dan berdasarkan perhitungan Slovin diperoleh sampel sebanyak 300 siswa. Teknik pengambilan sampel menggunakan proportional random sampling. Teknik analisis data menggunakan statistik deskriptif dan analisis regresi. Hasil penelitian menunjukkan bahwa pembelajaran kewirausahaan memiliki pengaruh yang signifikan dan positif terhadap minat berwirausaha siswa di era revolusi 4.0. Temuan ini menyiratkan bahwa untuk meningkatkan minat berwirausaha siswa di era revolusi 4.0 akan lebih efektif dengan meningkatkan proses pembelajaran kewirausahaan di sekolah.

\section{ABSTRACT}

Keywords:

Entrepreneurship Education Entrepreneurial Intention Revolutionary Era 4.0
Study of the Effect of Entrepreneurship Education on Student Entrepreneurial Intention in the Revolutionary Era 4.0. This study aims to determine and analyze the effect of entrepreneurial learning on student entrepreneurial interest in the revolutionary 4.0 era. Entrepreneurial learning is measured through indicators of entrepreneurship awareness education, education for start-up, education for entrepreneurial dynamic and contrning education for entrepreneurship. Entrepreneurial interest is measured through indicators of preference, desire and plan. The research method used was an explanatory survey method. Data collection techniques through the distribution of questionnaires distributed to students of Vocational High School (VHS) 2 Tasikmalaya. The research instrument was tested through validity and reliability testing. The population of this study was all students of SMK Negeri 2 Tasikmalaya as many as 1,545 students and based on Slovin's calculations a sample of 300 students was obtained. The sampling technique uses proportional random sampling. Data analysis techniques using descriptive statistics and regression analysis. The results showed that entrepreneurial learning had a significant and positive influence on student entrepreneurial interest in the revolutionary 4.0 era. This finding implies that to increase student interest in entrepreneurship in the 4.0 revolution era will be more effective by improving the entrepreneurial learning process in schools. 


\section{Pendahuluan}

Kewirausahaan merupakan ujung tombak dalam perekonomian sebuah negara. Selain sebagai sarana untuk meningkatkan pertumbuhan ekonomi jangka Panjang, kewirausahaan juga dapat meningkatkan kemakmuran ekonomi dan sosial melalui peningkatan pendapatan negara (Kruger, 2003; Alfonso, \& Cuevas, 2012). Berkat peran kewirausahaan yang sangat penting itulah, banyak negara mengupayakan warga negaranya untuk memiliki usaha sendiri dibandingkan bekerja di bawah pimpinan orang lain tidak terkecuali dengan negara Indonesia (Wicaksono \& Nuvriasari, 2012).

Kemampuan seseorang berwirausaha merupakan kemampuan pemberian, yang didapat tanpa adanya usaha yang cukup berarti, akan tetapi, kerangka konseptual tersebut saat ini tidak dapat dipertanggungjawabkan. Hal tersebut dikarenakan saat ini kebanyakan orang mulai berwirausaha tidak dimotivasi oleh kemampuan pemberian tersebut namun lebih dikarenakan oleh berbagai keadaan yang memotivasi seseorang untuk menjadi seorang wirausaha yang sebelumnya sudah merencanakan memiliki perilaku yang sesuai dengan pengelolaan kesempatan dan sumber daya yang tersedia (Kirkley, 2016).

Salah satu masalah kewirausahaan yaitu intensi kewirausahaan yang rendah terkait niat seseorang untuk memulai sebuah bisnis baru (Wijaya, 2007; Handaru, 2014). Minat kewirausahaan sangat penting untuk memahami proses kewirausahaan karena mereka mendahului setiap upaya dalam perilaku kewirausahaan, apabila kita dapat memahami apa yang telah menciptakan maksud untuk bertindak maka kita akan memiliki wawasan yang signifikan yang menjadi motivasi individu untuk bertindak karena semakin kuat niat untuk terlibat perilaku, maka semakin besar kemungkinan kinerja nya akan berjalan lebih baik. Penting untuk diingat bahwa niat juga dapat membentuk perilaku berikutnya ( Ajzen, 2001).

Minat berwirausaha di Indonesia masih sangat rendah khususnya lulusan SMK (Aprilianty, 2012; Shirokova, Osigevskyy \& Bogatyreva, 2015). Menurut Direktur Pembinaan SMK Ditjen Manajemen Pendidikan Dasar dan Menengah (Mandikdasmen) Joko Sutrisno pada tahun 2010 jumlah lulusan SMK yang menjadi wirausaha hanya satu hingga dua persen dari 950 ribu lulusan per tahun (Basri, Faiza, Nasir \& Nasrun, 2019; Siswadi, 2014). Padahal seharusnya dengan bekal kompetensi kejuruan yang bersifat praktis, lulusan SMK lebih mampu mengaplikasikan pengetahuan dan keterampilan dalam dunia kerja sampai tahap menciptakan lapangan kerja sendiri sebagai wirausahawan dibandingkan lulusan sekolah menengah lainnya (Utami, 2013; Lepoutre et al., 2013).

Rendahnya minat wirausaha siswa SMK menunjukkan kecenderungan mereka untuk berwirausaha setelah lulus SMK rendah (Marini \& Hamidah, 2014). Hal ini jika terus menerus dibiarkan maka dikhawatirkan akan memicu bertambahnya pengangguran seiring dengan bertambahnya jumlah lulusan serta sedikitnya lapangan kerja yang tersedia. Oleh karena itu, perlu adanya upaya untuk meningkatkan minat wirausaha siswa SMK (Mulyani, 2014; Aprilianty, 2012). Pendidikan tingkat menengah, khususnya SMK memiliki karakter yang unik dalam menghasilkan lulusan yang siap kerja, namun memiliki peluang besar untuk ikut mengembangkan ekonomi melalui kewirausahaan (Wibowo, 2011; Rae \& Carswell, 2001).

Pembelajaran kewirausahaan menjadi faktor penting dalam menumbuhkan dan mengembangkan keinginan, jiwa dan perilaku berwirausaha dikalangan generasi muda, karena pendidikan merupakan sumber sikap dan niat keseluruhan untuk menjadi wirausaha (Adnyana, Purnami, 2016; Sullivan, 2000). Pembelajaran tentang kewirausahaan saat ini sudah banyak digunakan sebagai mata pelajaran. Tujuannya tentu untuk menarik niat siswa dan memberikan teori tentang entrepreneurship. Pembelajaran kewirausahaan menjadi jembatan antara pengetahuan teoritis dan keterlibatan praktis di lapangan. Terkait dengan pengaruh pendidikan kewirausahaan tersebut, perlu adanya pemahaman tentang bagaimana mendorong lahirnya siswa agar memiliki niat menjadi enterpreneur muda sejak mereka berada dibangku pendidikan (Budy, 2017; Majdi, 2012).

Pembelajaran kewirausahaan merupakan penanaman nilai, kemampuan dan perilaku seseorang dalam kreasi dan berinovasi dalam membentuk jiwa wirausaha seseorang (Danuhadimedjo, 2010; Wibowo, 2012). Pembelajaran kewirausahaan dapat menghasilkan perilaku wirausaha dan jiwa kepemimpinan sesuai dengan karakter dalam diri siswa yang sangat terkait dengan cara mengelola usaha untuk membekali peserta didit agar dapat berusaha secara mandiri (Welter, 2005; Mauer, Neergaard, \& Linstad, 2017). Tujuan pembelajaran kewirausahaan tidak hanya diarahkan untuk menghasilkan pebisnis atau business entrepreneur, 
tetapi mencakup seluruh profesi yang didasari oleh jiwa wirausaha atau entrepreneur (Mahfud, 2012; Koranti, 2013). Pembelajaran kewirausahaan memberikan manfaat menumbuhkan sikap - sikap kewirausahaan dan memberikan keterampilan kewirausahaan. Selain itu komponen pembelajaran kewirausahaan terdiri dari tujuan, bahan ajar, evaluasi dan proses pembelajaran yang meliputi guru, metode pembelajaran, siswa, dan proses kegiatan belajar mengajar (Al Idrus, 2017; Zhao, Seibert \& Hills, 2005).

Penelitian mengenai pembelajaran kewirausahaan dan minat berwirausaha sudah banyak diteliti sebelumnya (Krueger, Reilly \& Carsrud, 2000; Minniti \& Bygrave, 2001). Penelitian sebelumnya belum meneliti di SMK Negeri di Tasikmalaya. Untuk itu penelitian ini dilakukan untuk mengetahui dan menganalisis pengaruh pengaruh pembelajaran kewirausahaan terhadap minat berwirausaha siswa era revolusi 4.0. Kajian ini diharapkan dapat berkontribusi dalam memberikan arah kebijakan kepada pemangku-pemangku kepentingan berkaitan dengan minat berwirausaha siswa di era revolusi 4.0 .

\section{Metode}

Metode penelitian yang digunakan dalam penelitian ini adalah metode explanatory survey. Populasi penelitian ini adalah siswa kelas XII dari 50 SMK di Kota Tasikmalaya sebanyak 6.553 siswa, dipilihnya kelas XII karena mereka sudah menerima materi berupa teori dan praktik tentang kewirausahaan selama 2 tahun. Berdasarkan perhitungan Slovin didapat sampel penelitian ini sebanyak 300 siswa dengan teknik pengambilan sampel proporsional probability sampling. Berdasarkan jenis kelamin siswa perempuan sebanyak 58\% dan siswa laki-laki sebanyak $42 \%$. Berdasarkan asal sekolah, SMK Negeri 1 Tasikmalaya sebanyak 38,33\%, SMK Negeri 2 Kota Tasikmalaya sebanyak 4\%, SMK Negeri 3 Tasikmalya sebanyak $27 \%$ dan SMK Negeri 4 Tasikmalaya sebanyak $30,66 \%$.

Pengukuran tingkat pembelajaran kewirausahaan indikator mengacu pada riset (Mestay, 2008) yaitu tingkat keterpaparan siswa dan efektivitas pembelajaran kewirausahaan. Pengukuran tingkat intensi berwirausaha indikator mengacu pada riset Carr \& Sequeira, (2007) yaitu desires, preferences, plan dan behavior expectatancies. Pengumpulan data dilakukan menggunakan kuesioner kemudian dianalisis menggunakan statistika deskriptif dan statistika inferensial. Data yang telah terkumpul dianalisis dengan sistem skoring skala likert 5 poin dari sangat tidak setuju (1) hingga sangat setuju (5) untuk mendapatkan data interval dan diberi skor atau nilai. Instrumen penelitian diuji melalui uji validitas dan uji realibitas. Pengujian hipotesis dilakukan dengan regresi berganda.

\section{Hasil dan pembahasan \\ Gambaran umum pembelajaran \\ kewirausahaan}

Berdasarkan perhitungan dan pengolahan data, maka dapat disusun distribusi frekuensi data pembelajaran kewirausahaan sebagai berikut:

\begin{tabular}{cccc}
\multicolumn{4}{c}{$\begin{array}{c}\text { Tabel 1. Distribusi Frekuensi Variabel } \\
\text { Pembelajaran Kewirausahaan (X1) }\end{array}$} \\
\hline No & $\begin{array}{c}\text { Kelas } \\
\text { Interval }\end{array}$ & Frekuensi & $\begin{array}{c}\text { Persentase } \\
(\%)\end{array}$ \\
\hline 1 & $29-30$ & 42 & 14 \\
2 & $31-32$ & 52 & 17,33 \\
3 & $33-34$ & 46 & 15,33 \\
4 & $35-36$ & 47 & 15,66 \\
5 & $37-38$ & 63 & 21,00 \\
6 & $39-40$ & 50 & 16,66 \\
\hline & Jumlah & $\mathbf{3 0 0}$ & $\mathbf{1 0 0}$
\end{tabular}

Sumber : Hasil Pengolahan Data, 2020

Berdasarkan Tabel 1, dapat diketahui bahwa frekuensi terbanyak terdapat pada kelas interval 37-38 dengan jumlah frekuensi yaitu 63 responden $(21,00 \%)$ dan frekuensi terkecil terdapat pada kelas interval 29-30 dengan jumlah frekuensi yaitu 4 responden (14\%).

Berdasarkan perhitungan dan pengolahan data, maka kategori pembelajaran kewirausahaan dapat dilihat pada Tabel 2 sebagai berikut.

Tabel 2. Kategori Variabel

Pembelajaran Kewirausahaan (X1)

\begin{tabular}{|c|c|c|c|c|}
\hline $\begin{array}{l}\mathbf{N} \\
\mathbf{0}\end{array}$ & $\begin{array}{c}\text { Kategor } \\
\text { i }\end{array}$ & $\begin{array}{c}\text { Kelas } \\
\text { Interva } \\
1\end{array}$ & $\begin{array}{c}\text { Frekuens } \\
\text { i }\end{array}$ & $\begin{array}{c}\text { Persentas } \\
\text { e (\%) }\end{array}$ \\
\hline 1 & Rendah & $29-32$ & 94 & 31,33 \\
\hline 2 & Sedang & $33-36$ & 93 & 31,00 \\
\hline 3 & Tinggi & $37-40$ & 113 & 37,66 \\
\hline \multicolumn{3}{|c|}{ Jumlah } & 300 & 100 \\
\hline
\end{tabular}

Sumber : Hasil Pengolahan Data, 2020 
Berdasarkan Tabel 2, dapat diketahui bahwa pembelajaran kewirausahaan (X1) dari 300 responden dapat dikatakan bahwa kategori tinggi sebanyak 113 responden dengan persentase $37,66 \%$, kategori sedang sebanyak 93 responden dengan persentase $31,00 \%$, dan kategori rendah sebanyak 94 responden dengan persentase $31,33 \%$. Sehingga dapat dikatakan bahwa pembelajaran kewirausahaan siswa SMK Negeri 2 Tasikmalaya tergolong tinggi yaitu ditunjukkan pada kelas interval 37-40 dengan persentase $37,66 \%$ atau 113 responden dari jumlah total responden sebanyak 300. Pembelajaran kewirausahaan tergolong tinggi artinya artinya pembelajaran wirausaha telah 1) entrepreneurial awareness education yaitu pendidikan kewirausahaan yang menekankan pada keinginan dan minat. 2) education for start-up yaitu pendidikan kewirausahaan yang mengacu pada kesiapan bisnis. 3) education for entrepreneurial dynamic yaitu pendidikan kewirausahaan yang mampu mempromosikan perilaku kewirausahaan yang dinamis, dan 4) contrinuining education for entrepreneurship yaitu pendidikan kewirausahaan sebagai upaya meningkatkan kemampuan yang telah ada.

\section{Gambaran Umum Minat Berwirausaha}

Berdasarkan perhitungan dan pengolahan data, maka dapat disusun distribusi frekuensi data minat berwirausaha sebagai berikut:

Tabel 3. Distribusi Frekuensi Variabel Minat Berwirausaha (Y)

\begin{tabular}{cccc}
\hline No & $\begin{array}{c}\text { Kelas } \\
\text { Interval }\end{array}$ & Frekuensi & $\begin{array}{c}\text { Persentase } \\
(\%)\end{array}$ \\
\hline 1 & $29-30$ & 39 & 13 \\
2 & $31-32$ & 48 & 16 \\
3 & $33-34$ & 38 & 12,66 \\
4 & $35-36$ & 45 & 15 \\
5 & $37-38$ & 75 & 25 \\
6 & $39-40$ & 55 & 18,33 \\
\hline & Jumlah & $\mathbf{3 0 0}$ & $\mathbf{1 0 0}$
\end{tabular}

Sumber: Hasil Pengolahan Data, 2020

Berdasarkan Tabel 3, dapat diketahui bahwa frekuensi terbanyak terdapat pada kelas interval 37-38 dengan jumlah frekuensi yaitu 75 responden $(25 \%)$ dan frekuensi terkecil terdapat pada kelas interval 29-30 dengan jumlah frekuensi yaitu 39 responden (13\%).
Berdasarkan perhitungan dan pengolahan data, maka kategori minat berwirausaha dapat dilihat pada Tabel 4 sebagai berikut.

Tabel 4. Kategori Variabel Minat

Berwirausaha (Y)

\begin{tabular}{|c|c|c|c|c|}
\hline $\begin{array}{l}\mathbf{N} \\
\mathbf{0}\end{array}$ & $\begin{array}{c}\text { Kategor } \\
\text { i }\end{array}$ & $\begin{array}{c}\text { Kelas } \\
\text { Interva } \\
l\end{array}$ & $\begin{array}{c}\text { Frekuens } \\
\text { i }\end{array}$ & $\begin{array}{c}\text { Persentas } \\
\text { e }(\%)\end{array}$ \\
\hline 1 & Rendah & $29-32$ & 87 & 29 \\
\hline 2 & Sedang & $33-36$ & 83 & 27,66 \\
\hline 3 & Tinggi & $37-40$ & 130 & 43,33 \\
\hline \multicolumn{3}{|c|}{ Jumlah } & 300 & 100 \\
\hline
\end{tabular}

\section{Sumber : Hasil Pengolahan Data, 2020}

Berdasarkan Tabel 4, dapat diketahui bahwa minat berwirausaha $(\mathrm{Y})$ dari 300 responden dapat dikatakan bahwa kategori tinggi sebanyak 130 responden dengan persentase 43,33\%, kategori sedang sebanyak 83 responden dengan persentase $27,66 \%$, dan kategori rendah sebanyak 87 responden dengan persentase $29 \%$. Sehingga dapat dikatakan bahwa minat berwirausaha siswa SMK Negeri 2 Tasikmalaya tergolong tinggi yaitu ditunjukkan pada kelas interval 37-40 dengan persentase 43,33\% atau 130 responden dari jumlah total responden sebanyak 300. Minat berwirausaha siswa tergolong tinggi artinya siswa telah memiliki 1) preference, merupakan sejauh mana seseorang memilih wirausaha sebagai pilihan karir dimasa yang akan datang dibanding memilih karir sebagai pekerja. 2) desire, merupakan keinginan individu untuk mandiri dan membuka usaha dimasa yang akan datang, dan 3) plan, merupakan keseriusan berpikir dan perencanaan mengenai pembukaan usaha baru.

\section{Pengaruh Pembelajaran Ekonomi terhadap Minat Berwirausaha}

Berdasarkan hasil analisis dan pengolahan data dapat diketahui bahwa terdapat pengaruh pembelajaran kewirausahaan terhadap minat berwirausaha. Hal ini dapat dibuktikan dengan hipotesis yang menunjukkan koefisien $t_{\text {hitung }}$ diperoleh sebesar 11,009 dan tabel sebesar 1,9971 dengan demikian $t_{\text {hitung }}>t_{\text {tabel }}$ atau 11,009 > 1,9971 hal ini berarti $\mathrm{H}_{0}$ ditolak dan $\mathrm{H}_{1}$ diterima, atau dengan kata lain pembelajaran kewirausahaan berpengaruh positif terhadap minat berwirausaha siswa SMK Negeri 2 Tasikmalaya. Hasil penelitian ini mendukung hasil-hasil penelitian sebelumnya (Krueger, Reilly 
\& Carsrud, 2000; Minniti \& Bygrave, 2001) yang menyatakan bahwa ada pengaruh yang positif dan signifikan pembeajaran kewirausahaan terhadap minat berwirausaha.

\section{Simpulan}

Berdasarkan hasil pengolahan dan analisis data, maka dapat disimpulkan bahwa pembelajaran kewirausahaan berada pada kategori tinggi dan minat berwirausaha siswa berada pada kategori sangat tinggi. Hasil penelitian ini menunjukkan bahwa hipotesis yang diajukan yaitu pembelajaran kewirausahaan memiliki pengaruh positif dan signifikan terhadap minat berwirausaha siswa di era revolusi 4.0 terbukti diterima. Hal ini menunjukkan bahwa pembelajaran kewirausahaan akan mempengaruhi minat berwirausaha siswa, sehingga pentingnya siswa untuk mengikuti pembelajaran kewirausahaan di sekolah dengan baik di era revolusi 4.0 ini agar memiliki minat berwirausaha mengingat di era revolusi 4.0 ini salah satu skill yang harus dimiliki oleh siswa adalah enterprenurship.

Berdasarkan hasil penelitian di atas penulis memberikan rekomendasi sebagai berikut 1) bagi siswa, sebaiknya perlu mengikuti pembelajaran kewirausahaan dengan baik untuk menambah pengetahuan dan keterampilan terkait kewirausahaan, selain itu siswa harus mengikuti pelatihan-pelatihan kewirausahaan memiliki minat dalam berwirausaha. 2) bagi pihak sekolah, memberikan pembelajaran kewirausahaan kepada siswa dengan baik tidak hanya secara teori tetapi juga secara praktik seperti mengadakan program magang dan pelatihan kewirausahaan dengan menjalin kerjasama dengan stakeholderstakeholder yang berkaitan dengan dunia usaha.

\section{Referensi}

Adnyana, I. G. L. A., \& Purnami, N. M. (2016). Pengaruh pendidikan kewirausahaan, self efficacy dan locus of control pada niat berwirausaha. EJurnal Manajemen Universitas Udayana, 5(2).

Al Idrus, S. (2017). Strategi pembelajaran kewirausahaan: aplikasi pembelajaran mata kuliah kewirausahaan di perguruan tinggi.
Aprilianty, E. (2012). Pengaruh kepribadian wirausaha, pengetahuan kewirausahaan, dan lingkungan terhadap minat berwirausaha siswa SMK. Jurnal pendidikan vokasi, 2(3).

Basri, I. Y., Faiza, D., Nasir, M., \& Nasrun, N. (2019). Implementasi Pembelajaran Berbasis Produk Dalam Rangka Menyiapkan Lulusan Smk Menjadi Wirausahawan Muda. INVOTEK: Jurnal Inovasi Vokasional dan Teknologi, 19(1), 43-52.

Budy, D. A. (2017). Pengaruh Pendidikan Kewirausahaan dan Motivasi Kewirausahaan Terhadap Keterampilan Berwirausaha Mahasiswa Universitas 17 Agustus 1945 Jakarta. Journal For Business and Entrepreneurship, 1(1).

Danuhadimedjo, R.D. 2008. Kewiraswastaan dan Pembangunan. Bandung : Alfabeta.

Guzmán-Alfonso, C., \& Guzmán-Cuevas, J. (2012). Entrepreneurial intention models as applied to Latin America. Journal of Organizational Change Management, 25(5), 721-735.

Handaru, A. W. (2014). Pengaruh Sikap, Norma Subjektif, dan Efikasi Diri terhadap Intensi Berwirausaha Mahasiswa Magister Management (Kajian Empiris pada Sebuah Universitas Negeri. Jurnal Universitas Paramadina, 11(2), 1046-1061.

Ilozor, B., Sarki, A., Hodd, M., Heinonen, J., \& Poikkijoki, S. A. (2006). An entrepreneurial-directed approach to entrepreneurship education: mission impossible?. Journal of management development.

Kirkley, W. W. (2016). Entrepreneurial behaviour: the role of 
values. International Journal of Entrepreneurial Behavior \& Research.

Krueger Jr, N. F., Reilly, M. D., \& Carsrud, A. L. (2000). Competing models of entrepreneurial intentions. Journal of business venturing, 15(5-6), 411-432.

Koranti, K. (2013). Analisis Pengaruh Faktoreksternal Dan Internal Terhadap Minat Berwirausaha. Prosiding PESAT, 5.

Krueger, N. F. (2003). The cognitive psychology of entrepreneurship. In Handbook of entrepreneurship research (pp. 105-140). Springer, Boston, MA.

Lepoutre, J., Justo, R., Terjesen, S., \& Bosma, N. (2013). Designing a global standardized methodology for measuring social entrepreneurship activity: the Global Entrepreneurship Monitor social entrepreneurship study. Small Business Economics, 40(3), 693-714.

Mahfud, T. (2012). Praksis pembelajaran kewirausahaan pada unit produksi jasa boga. Jurnal Pendidikan Vokasi, 2(1).

Majdi, M. Z. (2012). Pengaruh Pembelajaran Kewirausahaan, Internalisasi Nilai Kewirausahaan di Keluarga dan Motivasi Minat Berwirausaha. Educatio, 7(2), 1-15.

Marini, C. K., \& Hamidah, S. (2014). Pengaruh self-efficacy, lingkungan keluarga, dan lingkungan sekolah terhadap minat berwirausaha siswa SMK jasa boga. Jurnal Pendidikan Vokasi, 4(2).

Mauer, R., Neergaard, H., \& Linstad, A. K. (2017). Self-efficacy: Conditioning the entrepreneurial mindset. In Revisiting the entrepreneurial mind (pp. 293-317). Springer, Cham.

Minniti, M., \& Bygrave, W. (2001). A dynamic model of entrepreneurial learning. Entrepreneurship theory and practice, 25(3), 5-16.

Mulyani, E. (2014). Pengembangan Model Pembelajaan Berbasis Projek Pendidikan Kewirausahaan Untuk Meningkatkan Sikap, Minat, Perilaku Wirausaha, Dan Prestasi Belajar Siswa SMK. Jurnal Cakrawala Pendidikan, 33(1).

Rae, D., \& Carswell, M. (2001). Towards a conceptual understanding of entrepreneurial learning. Journal of small business and enterprise development.

Siswadi, Y. (2014). Analisis faktor internal, faktor eksternal dan pembelajaran kewirausahaan yang mempengaruhi minat mahasiswa dalam berwirausaha. Jurnal Ilmiah Manajemen dan Bisnis, 13(1).

Sullivan, R. (2000). Entrepreneurial learning and mentoring. International Journal of Entrepreneurial Behavior \& Research.

Utami, Y. G. D. (2013). Self efficacy dengan kesiapan kerja siswa sekolah menengah kejuruan. Jurnal Ilmiah Psikologi Terapan, 1(1), 40-52.

Welter, F. (2005). Entrepreneurial behavior in differing environments. In Local heroes in the global village (pp. 93-112). Springer, Boston, MA.

Wibowo, A. (2011). Pendidikan Kewirausahaan (konsep dan strategi). Yogyakarta: Pustaka Pelajar.

Wibowo, M. (2012). Pembelajaran kewirausahaan dan minat wirausaha lulusan SMK. Eksplanasi, 6(2). 
Wicaksono, G., \& Nuvriasari, A. (2012). Meningkatkan kinerja umkm industri kreatif melalui pengembangan kewirausahaan dan orientasi pasar: Kajian pada peran serta wirausaha wanita di kecamatan moyudan, kabupaten sleman, propinsi diy. Jurnal SosioHumaniora, 3(4).

Wijaya, T. (2007). Hubungan adversity intelligence dengan intensi berwirausaha (studi empiris pada siswa SMKN 7 Yogyakarta). Jurnal
Manajemen dan Kewirausahaan,9(2), 117-127.

Zhao, H., Seibert, S. E., \& Hills, G. E. (2005). The mediating role of self-efficacy in the development of entrepreneurial intentions. Journal of applied psychology, 90(6), 1265. 